\title{
Locus Coeruleus Stimulation by Corticotropin-Releasing Hormone Suppresses in vitro Cellular Immune Responses
}

\author{
Stefanie Rassnick, ${ }^{1}$ Alan F. Sved, ${ }^{2}$ and Bruce S. Rabin ${ }^{3}$ \\ Departments of ${ }^{1}$ Psychiatry, ${ }^{2}$ Neuroscience, and ${ }^{3}$ Pathology and The Brain, Behavior, and Immunity Center, University of \\ Pittsburgh, Pittsburgh, Pennsylvania 15213-2582
}

\begin{abstract}
Previous studies have demonstrated that stressors alter cellular immune system function, and increase the activity of locus coeruleus neurons. Furthermore, stressors increase the release of corticotropin-releasing hormone (CRH) and locus coeruleus neurons are activated by CRH. Thus, the present study examined whether activation of the locus coeruleus by infusion of $\mathrm{CRH}$ modulates the function of blood and spleen lymphocytes assessed in vitro. CRH (100 ng) was administered into the region of the locus coeruleus in awake rats $1 \mathrm{hr}$ before spleen and peripheral blood lymphocytes were collected for culture with nonspecific mitogens. Unilateral or bilateral microinfusion of $\mathrm{CRH}$ into the locus coeruleus produced a decrease in blood and spleen T-lymphocyte mitogenic responses to phytohemagglutinin, ConA, and an antibody to the T-lymphocyte antigen receptor. In contrast, infusion of saline into the locus coeruleus or CRH into the surrounding region of the dorsal pons did not alter spleen or blood lymphocyte responses. Plasma concentrations of adrenocorticotropic hormone, corticosterone, and IL- 6 were increased by CRH infusion into the locus coeruleus. These results suggest that $\mathrm{CRH}$-evoked activation of the locus coeruleus stimulates the hypophysial adrenal axis, possibly activates the sympathetic nervous system, and results in immunosuppression. Comparable changes in lymphocyte and hormone responses are produced by an aversive stimulus or a conditioned stressor, suggesting that activation of the locus coeruleus may be a component of stressor-induced immune alterations.
\end{abstract}

[Key words: locus coeruleus, corticotropin-releasing hormone, cellular immunity, rat, adrenocorticotropin hormone, corticosterone, interleukin-6]

Identifying the CNS substrates that modify immunologic function may lead to a better understanding of how stress influences immune reactivity in infectious, malignant, and autoimmune diseases. Research shows that cellular immune system function

\footnotetext{
Received Jan. 10, 1994; revised Mar. 22, 1994; accepted Apr. 7, 1994.

This research was supported by grants provided by the National Institute of Mental Health: MII434011 to B.S.R. and MII29670 to A.F.S. We acknowledge the expert technical assistance of Ada Armfield, Jennifer Litz, and David Maurer for assistance with the lymphocyte assays. A research protocol describing all aspects of the present report concerning the use of animals (care, maintenance, surgery, drug treatment, and sacrifice) was approved by the Animal Care Committee of The University of Pittsburgh.

Correspondence should be addressed to Stefanie Rassnick, Ph.D., Clinical Immunopathology-CLSI, University of Pittsburgh Medical Center, 200 Lothrop Street, Pittsburgh, PA 15213-2582.

Copyright (C) 1994 Society for Neuroscience $0270-6474 / 94 / 146033-08 \$ 05.00 / 0$
}

is suppressed by psychological and physical stressors and suggests that the modulatory effects of stress on immunologic responses is related to integrated CNS activity leading to activation of hypophysial and sympathetic hormonal systems (Rozman and Brooks, 1985; Solomon, 1987; Rabin et al., 1989; Danzer and Kelly, 1989; Cunnick et al., 1990; Keller et al., 1991).

Increased activity of corticotropin-releasing hormone systems (CRH) concomitant with stress may modulate immunologic responses (Irwin et al., 1987, 1992; Jain et al., 1991; Straubaugh and Irwin, 1992; Irwin, 1993) because autonomic, endocrine, and behavioral responses that are symptomatic of stress can be produced by intraventricular administration of CRH (Britton et al., 1982; Brown et al., 1982; Sutton et al., 1982; Eaves et al., 1985; Koob and Bloom, 1985; Fisher et al., 1989; Dunn and Berridge, 1990). Therefore, like stressors, endogenous CRH systems may modulate CNS transmission to produce regulatory effects on endocrine and immunologic responses.

One site at which $\mathrm{CRH}$ likely modulates CNS function during stress is the nucleus locus coeruleus in the dorsal pons (Foote et al., 1980; Butler et al., 1990; Swiergiel et al., 1992). Electrophysiological studies show that the locus coeruleus is activated by CRH (Ehlers et al., 1983; Valentino et al., 1983; Valentino and Foote, 1987, 1988; De Sarro et al., 1992) and exposure to noxious stimuli (Abercrombie and Jacobs, 1987). Furthermore, stressors increase activity of locus coeruleus neurons, as reflected by the expression of the immediate-early gene c-Fos (Pezzonc et al., 1993) and the activity of tyrosine hydroxylase, the rate limiting enzyme for norepinephrine biosynthesis (Zigmond et al., 1974; Richard et al., 1988; Weiner et al., 1991; Melia et al., 1992). Therefore, the integrative reactivity of the locus coeruleus and its projections (for review, see Foote et al., 1983; Moore and Card, 1984; Aston-Jones et al., 1991; Valentino et al., 1992) to sensory stimuli is the basis for the present hypothesis, which poses that activation of this nucleus is part of the neural circuit that modifies immunologic function.

Previous studies show that the locus coeruleus is activated by $\mathrm{CRH}$, is innervated by $\mathrm{CRH}$-like immunoreactive fibers (Merchenthaler et al., 1982; Cummings et al., 1983; Swanson et al., 1983; Sakanaka et al., 1987; Valentino et al., 1992) and contains binding sites for CRH (DeSouza, 1987). Therefore, the present study was designed to test whether activation of the locus coeruleus by CRH can modulate in vitro cellular immune system function. CRH or vehicle was administered into the locus coeruleus in conscious rats, and spleen and peripheral blood cells were cultured with nonspecific mitogens to evaluate lymphocyte prolifcrative responses. In addition, plasma samples were as- 
sayed for adrenocorticotrophic hormone (ACTH), corticosterone and interleukin-6 (IL-6) to determine whether CRH-evoked activation of the locus coeruleus modified hypothalamic-pituitary-adrenal function.

\section{Materials and Methods}

Subjects. Male Wistar rats (Harlan Sprague Dawley, Inc., Indianapolis, IN) were housed individually in stainless steel cages, and were maintained on a $12 \mathrm{hr}$ light $/ 12 \mathrm{hr}$ dark cycle (lights on at 0600); One week after arrival, rats weighing between 271 and $307 \mathrm{gm}$ were anesthetized with an inhalation anesthetic (1.5-3.0\% fluothane vaporized with reconstituted breathing air: $21 \%$ oxygen balanced with $79 \%$ nitrogen) and sterentaxically implanted with bilateral $10 \mathrm{~mm}, 30$ gauge stainless steel intracranial cannulas (Plastics One Inc., Roanoke, VA). Stereotaxic coordinates were, anteroposterior, -0.8 to $-1.1 \mathrm{~mm}$ from the interaural linc; latcral, $\pm 1.1 \mathrm{~mm}$ from the midline; and dorsoventral, $-4.1 \mathrm{~mm}$ from the skull surface at the point of entry. The incisor bar was positioned at $-3.4 \mathrm{~mm}$ below the interaural line (Paxinos and Watson, 1986). Cannulas were fastened to the skull with dental acrylic cement, secured with two stainless steel screws, and sealed with $10 \mathrm{~mm}$ wire stylets. Following a $5 \mathrm{~d}$ recovery period, animals were habituated to the microinfusion procedure for $2 \mathrm{~d}$ prior to experimentation. Forty-eight hours before testing, the injectors $(13 \mathrm{~mm}, 33$ gauge) were inserted through the guide cannulas without extending beyond the length of the guide cannulas; then, $24 \mathrm{hr}$ before testing, the injectors were inserted all the way through the guide cannula aiming at the locus coeruleus.

Drug administration. Corticotropin-releasing hormone (CRH, Human, Rat Bachem California, Torrance, CA) was dissolved in $0.9 \%$ sterile, pyrogen-free, sodium chloride solution and prepared as $100 \mathrm{ng} /$ $0.5 \mu \mathrm{l}$. Animals were randomly assigned to receive bilateral microinfusion of either vehicle or CRH solution. While gently restraining the animals, CRH or vehicle solution was administered bilaterally $(0.5 \mu \mathrm{l}$, $1.5 \mathrm{~min}$ ) with cannula injectors that were connected to calibrated sterile polyethylene tubing, $10 \mu \mathrm{l}$ Hamilton syringes (Hamilton, Reno, NV), and a microinfusion pump (Razel Scientific Instruments Inc., Stamford, $\mathrm{CN}$ ). The injectors were left in place for $90 \mathrm{sec}$ before removal. The dummy stylets were replaced into the guide cannulas and the animals were returned to their home cages, where they remained for $\mathrm{l} \mathrm{hr}$ until the time of sacrifice.

Blood and spleen collection. Animals were sacrificed by cervical dislocation and a ventral incision was made to expose the ascending abdominal aorta. For each subject, a blood sample (approximately $3 \mathrm{ml}$ ) was collected from the abdominal aorta using a sterile syringe and vacutainer containing sodium heparin (45 USP units; Becton Dickinson, Rutherford, NJ), and then an additional blood sample $(2 \mathrm{ml})$ was collected into a vacutainer containing EDTA (tripotassium salt, $3.6 \mathrm{mg}$; Becton Dickinson).

For the mitogen-stimulated blood lymphocyte proliferation assays, $0.5 \mathrm{ml}$ of heparinized blood was immediately added to $4.5 \mathrm{ml}$ of RPMI 1640 tissue culture medium (GIBCO) supplemented with $10 \mathrm{mM}$ HEPES, $2 \mathrm{mM} \mathrm{L-glutamate}$, and $50 \mu \mathrm{g} / \mathrm{ml}$ gentamicin sulfate (all from GIBCO). The remaining blood was kept on ice, and then centrifuged (2000 rpm, $-4^{\circ} \mathrm{C}, 15 \mathrm{~min}$ ). Plasma samples were placed into siliconized, sterile, microcentrifuge tubes and stored frozen at $-70^{\circ} \mathrm{C}$ for $\mathrm{ACTH}$, corticosterone, and IL-6 assays.

Spleens were removed and placed in sterile polypropylene tubes containing $7 \mathrm{ml}$ of supplemented culture medium.

Mitogen-stimulated lymphocyte proliferation assays. Sterile laboratory equipment was used for the in vitro cell proliferation assays. Mitogen-stimulated spleen and blood lymphocyte responses were determined using assays of spleen and blood cell cultures prepared with the T-cell mitogens, phytohemagglutinin (PHA) type HA-16 (Wellcome), and concanavalin-A (ConA; Difco, Detroit, MI), which are plant lectins. Spleen lymphocyte cell cultures were also prepared with a B-cell mitogen, lipopolysaccharide (LPS; Difco), which is component of the cell walls of gram-negative bacteria. In addition, cultures were prepared to measure the spleen T-lymphocyte proliferative responses to a mouse monoclonal antibody to rat $\alpha / \beta$ T-cell antigen receptor (Ab TCR; total protein, $27 \mathrm{mg} / \mathrm{ml}$; Pharmingen, San Diego, CA). PHA, ConA, LPS, and the Ab TCR were each prepared in supplemented culture medium. Lymphocyte proliferation was stimulated with concentrations of mitogens that produce suboptimal and optimal proliferation in our laboratory (Cunnick et al., 1990; Lysle et al., 1990a).
For the spleen lymphocyte assays, the Ab TCR was diluted in supplemented culture medium $(1: 200)$ and was added to the culture plates (96-well, flat bottom, microtiter plates; Costar no. 3696) $24 \mathrm{hr}$ prior to the experiment to allow the antibody to bind to the plates. The microtiter plate wells containing the Ab TCR were washed three times with Hanks' Balanced Salt Solution (GIBCO, Grand Island, NY), and then $100 \mu \mathrm{l}$ of supplemented culture medium was added to these microtiter plate wells. PHA (5 and $10 \mu \mathrm{g} / \mathrm{ml})$, ConA (5 and $10 \mu \mathrm{g} / \mathrm{ml})$, and LPS ( 10 and $20 \mu \mathrm{g} / \mathrm{ml}$ ) were each added in triplicate to the other wells of the microtiter plates.

Spleens were dissociated into a single cell suspension by gently grinding the spleens between the frosted edges of microscope slides with supplemented culture medium that contained $10 \%$ heat-inactivated fetal calf serum (GIBCO) (designated as complete medium). The dispersed spleen cells were transferred to polypropylene tubes and allowed to stand for approximately $10 \mathrm{~min}$ in $10 \mathrm{ml}$ of complete medium, and the supernatant suspension was then transferred to a new tube. The concentration of nucleated cclls in the splccn samples was detcrmined in a Coulter Counter (model ZBI) and adjusted to $5 \times 10^{6}$ cells $/ \mathrm{ml}$ using complete culture medium. Aliquots of the single cell suspension $(100$ $\mu$ ) for each spleen sample were added to the culture plates. Background level of radioactivity was determined by adding $100 \mu \mathrm{l}$ of supplemented culture medium instead of mitogens to the microtiter plate wells. All cell cultures were placed into a temperature $\left(37^{\circ} \mathrm{C}\right)$ humidity $(67 \%)$ controlled, $\mathrm{CO}_{2}(5 \%)$ incubator.

The incorporation of thymidine into newly formed DNA during lymphocyte proliferation, the dependent measure of the in vitro cellular immune response, was assayed by adding ${ }^{3} \mathrm{H}$-thymidine $(1 \mu \mathrm{Ci} /$ well; specific activity, $6.7 \mathrm{Ci} / \mathrm{mmol}$; DuPont-New England Nuclear) to the spleen cell cultures during the last $5 \mathrm{hr}$ of a $48 \mathrm{hr}$ incubation period. The cell cultures were then harvested onto filtermat paper using a Skatron semiautomatic cell harvester and the incorporation of ${ }^{3} \mathrm{H}$-thymidine was determined by a liquid scintillation counter (Packard Tri-Carb 1500 beta-counter).

Blood lymphocyte cell cultures were processed using a similar assay method with the following differences: aliquots $(100 \mu$ l) of the blood samples (diluted 1:10 in supplemented medium as described in the blood collection section) were added to microtiter plates containing PHA $(2.5$ and $5 \mu \mathrm{g} / \mathrm{ml})$ and ConA ( 5 and $10 \mu \mathrm{g} / \mathrm{ml})$, and the ${ }^{3} \mathrm{H}$-thymidine was added to the cultures during the last $18 \mathrm{hr}$ of a $96 \mathrm{hr}$ incubation period. The number of leukocytes per milliliter of whole blood for each sample was determined using a Unopette and hemocytometer.

Hormone assays. Plasma samples from blood collected in EDTAtreated and heparin-treated vacutainer tubes were assayed for ACTH and corticosterone, respectively. Plasma samples were assayed in duplicate for ACTH and corticosterone using radioimmunoassay kits (ICN Biomedicals, Inc).

Plasma assay of $I L-6$. Plasma samples were assayed for IL-6 activity using a B9 plasmacytoma cell bioassay. Duplicates of the plasma samples (from blood collected in heparin-treated tubes) were diluted serially (beginning with a 1:4 dilution) with supplemented medium containing $5 \%$ heat-inactivated fetal calf serum in 96-well, flat bottom, microtiter plates. B9 cells were washed twice by suspending the cells in $40 \mathrm{ml}$ of Hanks' Salt Solution and centrifugation at $2100 \mathrm{rpm}$ for $10 \mathrm{~min}$. Then, the $B 9$ cells were suspended in complete medium containing $5 \times 10^{-5}$ M 2-mercaptoethanol, and centrifuged again. Finally, the cell concentration was adjusted to $1 \times 10^{\mathrm{s}} \mathrm{cell} / \mathrm{s} / \mathrm{ml}$ using complete medium containing $5 \times 10^{-5} \mathrm{M} 2$-mercaptoethanol, and added (100 $\mu \mathrm{l}$ per well) to the cultures plates. During the last $4 \mathrm{hr}$ of a $72 \mathrm{hr}$ incubation period, the cultures were incubated with ${ }^{3} \mathrm{H}$-thymidine $(1 \mu \mathrm{Ci} /$ well), and harvested. Proliferation values expressed as $\mathrm{cpm}$ were compared against a standard curve for recombinant human IL-6 $(80 \mathrm{pg} / \mathrm{ml})$ (BRMP, Frederick, MD). Plasma concentrations of IL- 6 were calculated as the dilution necessary to achieve $50 \%$ of the maximal proliferation in the experimental sample divided by the dilution necessary to achieve $50 \%$ of the maximal proliferation in the standard sample, multiplied by 80 $\mathrm{pg} / \mathrm{ml}$. The sensitivity of this assay is approximately $1 \mathrm{pg} / \mathrm{ml}$ and the specificity of this assay was confirmed using an IL-6 neutralizing antibody (R\&D Systems) (Zhou et al., 1993).

Assessment of injection site. At the end of the experiment, brains were rapidly removed and stored frozen. Brains were sectioned coronally at $40 \mu \mathrm{m}$ intervals on a cryostat, and then mounted onto glass slides and stained with cresyl violet. Infusion sites were verified under a light microscope. Cannula placements for infusion were judged to be within 


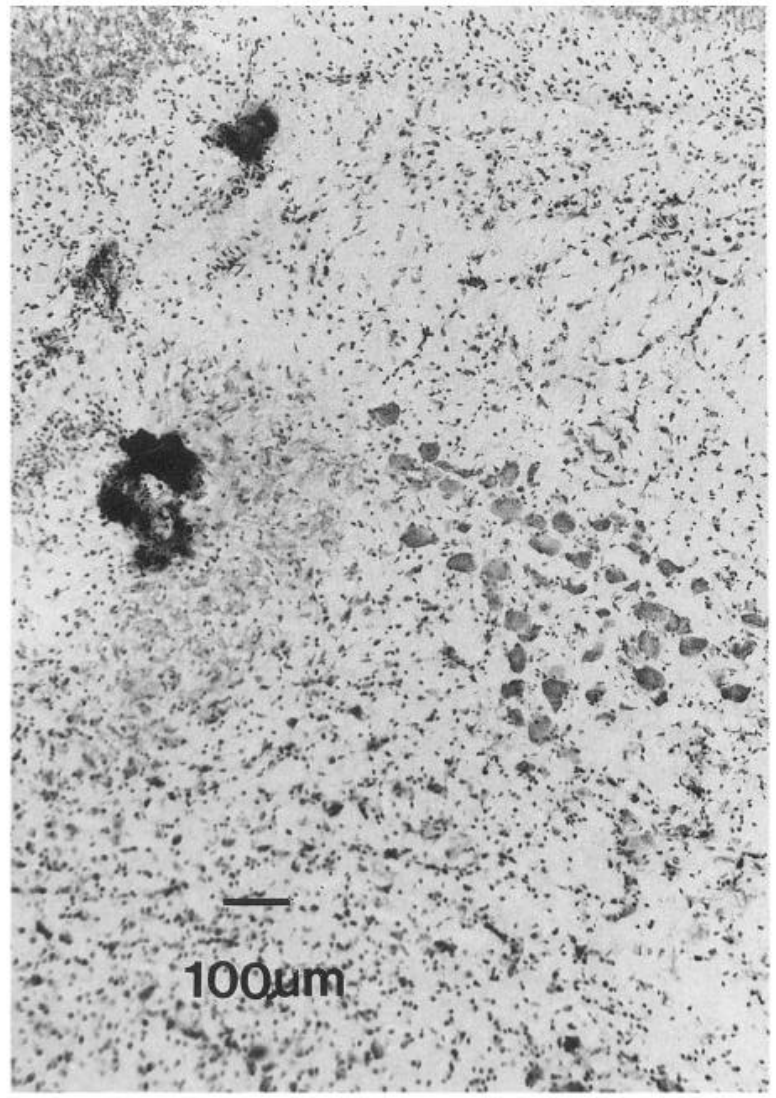

Figure 1. Histological localization of cannula placement within the locus coeruleus for animals receiving infusions of vehicle or CRH into the locus coeruleus. Note the cannula track extending into the locus coeruleus. This placement is typical of those included as infusions into the locus coeruleus. Scale bar, $100 \mu \mathrm{m}$.

the locus coeruleus when the cannula tracks were clearly within approximately $0.15 \mathrm{~mm}$ (medial-lateral) of the locus coeruleus neurons and located -10.3 to $-9.16 \mathrm{~mm}$ anteroposterior from bregma (Paxinos and Watson, 1986).

Experimental design. This study was conducted as a series of four cohorts, each using an identical experimental design, a representative number of subjects in each treatment group and a total of 12-17 animals. In each cohort, a separate group of unhandled rats (unoperated control group) was included to control for the effects of handling and surgery prior to experimentation. Samples for this group were processed identically to sample preparation for the other treatment groups. The study included 54 rats, with 34 of these rats receiving either vehicle or CRH infusions aimed at the locus coeruleus.

Statistical analysis. Data for the spleen cell proliferation were expressed as counts per minute (cpm) and data for the blood cell proliferation were normalized to $\mathrm{cpm}$ per $10^{5}$ leukocytes. Data for blood lymphocyte responses in two subjects that received vehicle into the locus coeruleus were uninterpretable due to technical error and were not included in the statistical analyses.

For each experimental sample, the background level of radioactivity (average of the triplicate $\mathrm{cpm}$ of unstimulated cell response) was subtracted from the mitogen-stimulated response (average of the triplicate cpm). Blood and spleen lymphocyte responses to each mitogen were analyzed separately using two-way analysis of variance (ANOVA) with a between-subjects factor for treatment group (control, vehicle into the locus coeruleus, and CRH into the locus coeruleus) and a within-subjects factor for mitogen concentration. Individual group means were compared using Newman-Keuls a posteriori test.

Plasma concentrations of ACTH, corticosterone, and IL- 6 were transformed to logarithms and these data were analyzed by one-way ANOVA, followed by Newman-Keuls test for pairwise comparisons.

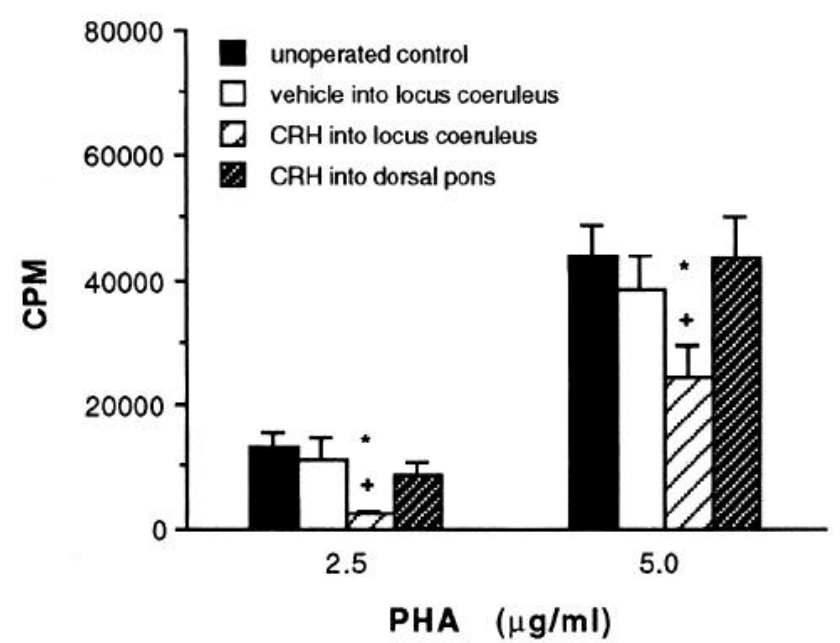

Figure 2. Blood lymphocyte mitogenic responses to PHA. The data are expressed as mean $( \pm$ SEM) specific stimulated proliferative response. Asterisks indicate significant differences in responses as compared with responses in the vehicle into the locus coeruleus group (Newman-Keuls test, $p<0.05$ ), and pluses indicate significant differences in responses relative to the control group $(p<0.05)$.

For statistical analyses, data for vehicle infusions that were not localized to the locus coeruleus were excluded. Data for the CRH infusions into the surrounding regions of the locus coeruleus dorsal pons formed a separate group to control for the specificity of CRH's actions on locus coeruleus activity, and responses in this group were compared with responses in the CRH into the locus coeruleus group using Student's $t$ test.

\section{Results}

Data for the LC infusion groups were based on histological determination of infusion sites that were within approximately $150 \mu \mathrm{m}$ of the LC neurons (Fig. 1). Histological examination of infusion sites showed that 10 of the 16 vehicle infusions were localized to the locus coeruleus. Of the 18 rats receiving $\mathrm{CRH}$ infusions aimed at the locus coeruleus, histological analysis showed that five of $\mathrm{CRH}$ infusions were administered bilaterally, seven $\mathrm{CRH}$ infusions were administered unilaterally into the locus coeruleus, and six $\mathrm{CRH}$ infusions were administered into the region of the dorsal pons surrounding the locus coeruleus. Mitogenic responses of spleen and blood lymphocytes after unilateral or bilateral infusion of $\mathrm{CRH}$ into the locus coeruleus were equivalent (Student's $t$ test; all comparisons, $p>$ 0.05 ); therefore, these data were pooled for statistical analyses. The numbers of subjects for each of the statistical tests were $n$ $=20$ for the unoperated control group, $n=12$ for $\mathrm{CRH}$ infusion into the locus coeruleus, and $n=6$ for the $\mathrm{CRH}$ infusion into the dorsal pons group. Data from 10 subjects that received vehicle infusion into the locus coeruleus were used for all the statistical tests except for analyses of blood lymphocyte responses, where $n=8$ subjects.

Infusion of $\mathrm{CRH}$ into the locus coeruleus decreased peripheral blood lymphocyte mitogenic responses to PHA (Fig. 2). ANOVA revealed that there was a significant main effect of treatment on blood lymphocyte responses to PHA $[F(2,37)=4.55 ; p<$ $0.05]$, a main effect of PHA concentration $[F(1,37)=84.59 ; p$ $<0.0001]$, and no significant treatment $\times$ PHA concentration interaction $[F(2,37)=0.73 ; p=0.49]$. The differences in blood lymphocyte responses to PHA after CRH infusion into the locus 


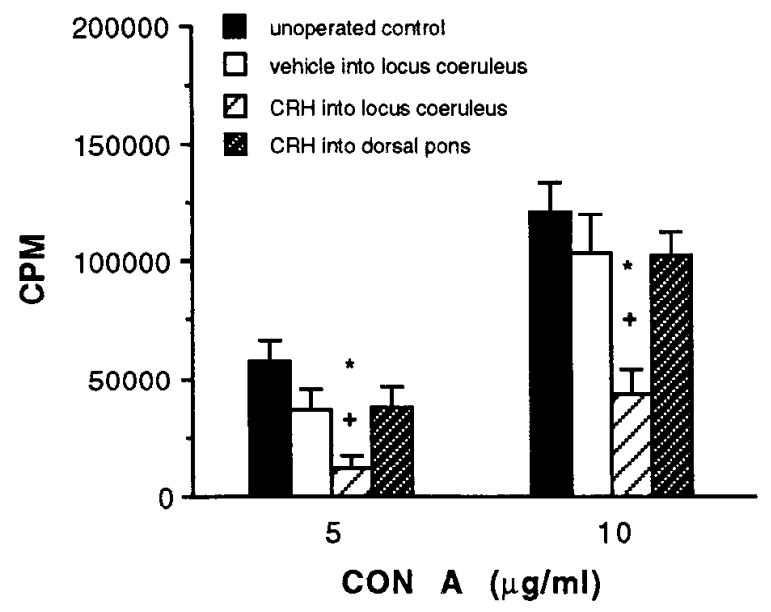

Figure 3. Blood lymphocyte mitogenic responses to ConA. The data are expressed as mean $( \pm$ SEM) specific stimulated proliferative response. Asterisks indicate significant differences in responses as compared with responses in the vehicle into the locus coeruleus group (Newman-Keuls te $\mathrm{t}, p<0.05$ ), and pluses indicate significant differences in responses relative to the control group $(p<0.05)$.

coeruleus as compared with CRH infusion into the dorsal pons were statistically significant $[t(16)=-3.4$ and $-2.2, p<0.05$, for 2.5 and $5 \mu \mathrm{g} / \mathrm{ml}$ PIIA, respectively].

Infusion of CRH into the locus coeruleus also decreased peripheral blood lymphocyte mitogenic responses to ConA (Fig. 3). ANOVA revealed a significant main effect of treatment on blood lymphocyte responses to ConA $[F(2,37)=9.35 ; p<$ $0.001]$ and ConA concentration $[F(1,37)=48.62 ; p<0.001]$, and no significant treatment $\times$ ConA concentration interaction $[F(2,37)=2.12 ; p=0.13]$. The differences in blood lymphocyte responses to CON A after CRH infusion into the locus coeruleus as compared with $\mathrm{CRH}$ infusion into the dorsal pons were statistically significant $[t(16)=-2.76$ and $-3.4, p<0.05$, for 5.0 and $10 \mu \mathrm{g} / \mathrm{ml}$ ConA, respectively].

Splenic lymphocyte mitogenic responses to PHA were de-

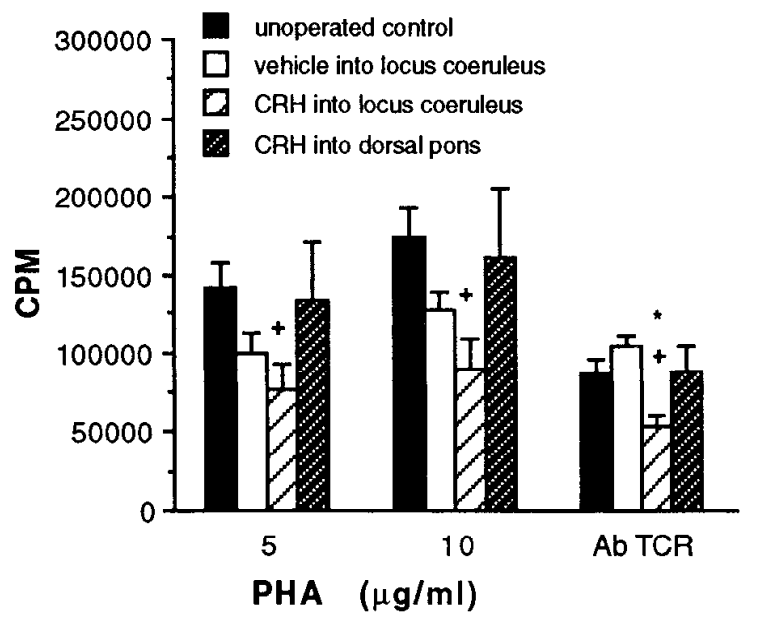

Figure 4. Spleen lymphocyte proliferative responses to PHA and the $\mathrm{Ab}$ TCR. The data are expressed as mean $( \pm$ SEM) specific stimulated proliferative responsc. Asterisks indicate significant differences in responses as compared with responses in the vehicle into the locus coeruleus group (Newman-Keuls test, $p<0.05$ ), and pluses indicate significant differences in responses relative to the control group $(p<0.05)$.



Figure 5. Splenic lymphocyte mitogenic response to ConA and LPS. The data are expressed as mean ( \pm SEM) specific stimulated proliferative response. Asterisks indicate significant differences in responses as compared with responses in the vehicle into the locus coeruleus group (Newman-Keuls test, $p<0.05$,) and pluses indicate significant differences in responses relative to the control group $(p<0.05)$.

creased by infusion of CRH into the locus coeruleus (Fig. 4). ANOVA revealed that there was a main effect of treatment on spleen lymphocyte responses to $\operatorname{PHA}[F(2,39)=4.50 ; p<0.05]$, a main effect of PHA concentration $[F(1,39)=24.24 ; p<0.001]$, and no significant treatment $\times$ PHA concentration interaction $[F(2,39)=1.38 ; p=0.26]$. The proliferative responses to PHA after CRH infusion into the locus coeruleus were not statistically different from the proliferative responses to PHA after CRH infusion into the dorsal pons [for 5.0 and $10 \mu \mathrm{g} / \mathrm{ml} \mathrm{PHA,} \mathrm{re-}$ spectively: $t(16)=-1.59, p=0.13$; and $t=-1.7, p=0.11$ ).

The splenic lymphocyte proliferative response to the Ab TCR was decreased by CRH administration into the locus coeruleus $[F(2,39)=6.81 ; p<0.005$; see Fig. 4]. Splenic lymphocyte responses to the $A b$ TCR after CRH infusion into the locus coeruleus were significantly different from responses after $\mathrm{CRH}$ infusion into the dorsal pons $(t=2.25 ; p<0.05)$.

The splenic lymphocyte proliferative response to ConA was decreased by CRH administration into the locus coeruleus. For lymphocyte responses to ConA, there was a main effect of treatment $[F(2,39)=5.31 ; p<0.01]$, a main effect of ConA concentration $[F(1,39)=198.93 ; p<0.001]$, and no significant treatment $\times$ ConA concentration interaction $[F(2,39)=1.29$; $p=0.28$ ]. The differences in splenic lymphocyte responses to ConA after $\mathrm{CRH}$ infusion into the locus coeruleus as compared with CRH infusion into the dorsal pons were marginally significant (for 2 and $5 \mu \mathrm{g} / \mathrm{ml}$ ConA, respectively: $t=-2.0, p=$ 0.06 ; and $t=-1.9, p=0.08$ ).

In contrast, $\mathrm{CRH}$ administration into the locus coeruleus did not alter LPS-stimulated spleen lymphocyte responses (Fig. 5). ANOVA on splenic lymphocyte responses to LPS showed no significant effects of treatment $[F(2,39)=1.0 ; p=0.36]$ or LPS concentration $[F(1,39)=1.3 ; p=0.26]$, and no treatment $\times$ LPS concentration $[F(2,39)=0.18 ; p=0.83]$.

Plasma concentrations of ACTH, corticosterone and IL-6 were increased after infusion of CRH into the locus coeruleus as 
Table 1. Plasma concentrations of ACTH, corticosterone, and IL-6 after CRH infusion into the locus coeruleus

\begin{tabular}{lccc} 
Treatment group & ACTH $(\mathrm{pg} / \mathrm{ml})$ & $\begin{array}{l}\text { Corticosterone } \\
(\mu \mathrm{g} / \mathrm{dl})\end{array}$ & $\begin{array}{l}\text { IL-6 } \\
(\mathrm{pg} / \mathrm{ml})\end{array}$ \\
\hline Unoperated control & $25.20(2.51)$ & $6.52(1.90)$ & $2.61(1.40)$ \\
Vehicle into the locus coeruleus & $58.66(20.63)$ & $12.03(5.61)$ & $48.30(16.48)^{*}$ \\
CRH into the locus coeruleus & $196.11(49.26)^{*}$ & $45.04(6.03)^{*}$ & $172.88(59.77)^{*}$ \\
CRH into dorsal pons & $129.48(29.77)$ & $27.27(6.30)$ & $68.23(14.58)$ \\
\hline
\end{tabular}

Data are presented as mean ( \pm SEM).

* Significant differences in plasma hormone concentrations as compared with the unoperated control group or the group that received vehicle infusion in the locus coeruleus (Newman-Keuls test, $p<0.01$ ).

compared with vehicle infusion into the locus coeruleus or the treatment control groups (Table 1). Plasma concentrations of ACTH, corticosterone and IL-6 were transformed to logarithms due to the unequal error variance across treatment groups (see Table 1). ANOVA on logarithmic transformed data showed a main effect of treatment for ACTH $[F(2,39)=25.75 ; p<0.0001]$, corticosterone $[F(2,39)=22.65 ; p<0.0001]$, and IL-6 $[F(2,39)$ $=40.07 ; p<0.0001]$. The average concentrations of ACTH, corticosterone, and IL-6 were greater after $\mathrm{CRH}$ infusion into the locus coeruleus than after $\mathrm{CRH}$ infusion into the dorsal pons; however, these differences did not reach statistical significance $[t(16)=0.7,1.7,1.7, p>0.1$, for ACTH, corticosterone, and IL-6, respectively].

\section{Discussion}

The results of the present study show that infusion of $\mathrm{CRH}$ into the locus coeruleus decreased spleen and peripheral blood lymphocyte mitogenic responses. This response is specific to T-lymphocytes because CRH-evoked activation of the locus coeruleus decreased lymphocyte responses to mitogens that selectively stimulate T-lymphocyte proliferation (PHA, ConA, and an antibody to the T-cell receptor). Furthermore, CRH infusion into the locus coeruleus did not alter splenic lymphocyte proliferative responses to LPS, a mitogen that selectively stimulates differentiation of B-lymphocytes. Comparable alteration of lymphocytc function are produced by strcss (Lysle ct al., 1988, 1990a; Maier et al., 1988; Cunnick et al., 1990). However, more research is needed to understand why $\mathrm{T}$-cell responses are consistently altered by stressors and B-cell responses are not (Komori et al., 1987; Lysle et al., 1990a,b). Thus, the data are consistent with the notion that CRH infused into the locus coeruleus mimics the immunosuppressive effects induced by stress and are consistent with the hypothesis that CRH into the locus coeruleus is involved in stressor-induced immune alterations.

The hypothesis that CRH in the locus coeruleus mediates the effects of stress on immune system function is supported by additional evidence. Locus coeruleus neurons are activated by CRH and stress (Korf et al., 1973; Ehlers et al., 1983; Valentino et al., 1983; Abercrombie and Jacobs, 1987; Valentino and Foote, 1987, 1988; Lachuer et al., 1991; Weiner et al., 1991; De Sarro et al., 1992; Curtis et al., 1993; Pezzone et al., 1993). Also, responses that are symptomatic of stress are produced by administration of CRH into the brain (Britton et al., 1982; Brown et al., 1982; Sutton et al., 1982; Eaves et al., 1985; Koob and Bloom, 1985; Fisher et al., 1989). The locus coeruleus receives CRH-containing afferents (Merchenthaler et al., 1982; Cummings et al., 1983; Swanson et al., 1983; Sakanaka et al., 1987;
Valentino et al., 1992), and these afferents are influenced by stress, as indicated by an increase in the concentration of $\mathrm{CRH}$ in the locus coeruleus in response to stress (Chapell et al., 1986). Furthermore, the effects of certain noxious stimuli on locus coeruleus neuronal activity can be blocked by antagonists of the CRH rcceptor (Valentino and Wehby, 1988; Valentino et al., 1991).

The present results also indicate the infusion of CRH into the locus coeruleus produces another response similar to that evoked by stressful stimuli: activation of the hypothalamic-pituitaryadrenal axis. Activation of this system following administration of $\mathrm{CRH}$ into the locus coeruleus is reflected by increases in plasma concentrations of ACTH, corticosterone, and IL-6, and confirms a previous report that $\mathrm{CRH}$ infused into the locus coeruleus increases plasma corticosterone levels (Butler et al., 1990). The increase in the circulating concentrations of each of these hormones is similar to that observed following exposure of rats to moderate stressors, such as low-intensity footshock (Zhou et al., 1993). Activation of the hypothalamic-pituitaryadrenal axis by infusion of $\mathrm{CRH}$ into the locus coeruleus is consistent with previous reports suggesting that activation of locus coeruleus noradrenergic neurons increases the release of ACTH and corticosterone (Plotsky et al., 1989; Carlson and Gann, 1991; Mezey and Palkovits, 1991; Thrivikraman et al., 1993).

Activation of the hypothalamic-pituitary-adrenal axis by infusion of $\mathrm{CRH}$ into the locus coeruleus may contribute to the suppression of blood lymphocyte mitogenic responses. Previous work in our laboratory shows that hormone secretion from the adrenal is an essential mediator of stress-induced suppression of mitogenic responses of peripheral blood lymphocytes (Cunnick et al., 1990). Furthermore, an adrenal-dependent release of IL-6 comprises part of the hormonal responses to stress (Zhou et al., 1993), suggesting that the increase in plasma concentrations of IL- 6 by infusion of CRH into the locus coeruleus may reflect an increase in adrenal secretion of IL-6 (Judd et al., 1990). Therefore, stress and locus coeruleus activation share an ability to increase hormone secretion from the pituitary and adrenal glands.

Adrenal cortical responses may contribute to the decreased mitogenic responses of blood lymphocytes. However, further study is necessary to determine whether the decreases in blood lymphocyte responses by CRH-evoked activation of the locus coeruleus are dependent upon corticosterone, because some studies show that blood lymphocyte responses are independent of corticosterone (Keller et al., 1983; Jain et al., 1991; Pczzonc et al., 1992). In addition, the present findings showed increased plasma concentrations of corticosterone (also $\mathrm{ACTH}$ ) in some 
animals after vehicle infusion into the locus coeruleus and $\mathrm{CRH}$ infusion into the dorsal pons that were not associated with decreased mitogenic responses of blood lymphocytes (see Table 1, Figs. 2, 3). The increases in hormone concentrations in the vehicle-treated and the CRH dorsal pons groups probably reflect activation of the hypophysial-adrenal axis that resulted from handling during infusion. Furthermore, the increase in plasma concentrations of corticosterone and $\mathrm{ACTH}$ after infusion of $\mathrm{CRH}$ into the dorsal pons suggest that some CRH infusions that were just outside the region of the locus coeruleus had effected the function of locus coeruleus neurons. Further study is necessary to determine the mechanisms by decreased blood lymphocyte responses occur as a function of the extent of locus coeruleus activation.

The decreased mitogenic response of splenic T-lymphocytes elicited by $\mathrm{CRH}$ infusion into the locus coeruleus most likely results from activation of the sympathetic nervous system. Previous studies have shown that stress-induced suppression of spleen lymphocyte mitogenic responses can be blocked by transection of the splenic nerve (Wan et al., 1993) or pharmacological inhibition of the sympathetic input to the spleen with $\beta$-adrenergic receptor antagonists (Cunnick et al., 1990). However, data on the effects of activating the locus coeruleus neurons on sympathetic neural activity are controversial. Whereas several studies have demonstrated sympathetic activation in response to electrical stimulation of the region of the locus coeruleus (Philippu et al., 1974; Ward and Gunn, 1976), the noradrenergic neurons of the locus coeruleus do not appear to be responsible for this effect (Sved and Felsten, 1987). In addition, stimulation of the locus coeruleus in anesthetized rats by local injection of excitatory drugs elicits a decrease in blood pressure (Sved and Felsten, 1987), and sympathetic neural activity (Miyawaki et al., 1991). Thus, future studies will be required to clarify the role of the sympathetic nervous system in mediating the suppression of lymphocyte responses that is produced by increased locus coeruleus activity.

The present findings may lead to clinical questions concerning the competency or reactivity of the immune system in patients who have functional changes in locus coeruleus activity. Relevant populations include patients experiencing chronic stress (Chapell et al., 1986; Richard et al., 1988; Melia and Duman, 1991), or neuropsychiatric disorders that may be associated with a hypersection of CRH (Holsboer et al., 1984; Nemeroff et al., 1984; Gold et al., 1986), and (NS diseases that are associated with a depletion of locus coeruleus neurons (Tavalato and Argenteiro, 1980; Singh et al., 1987; Chan-Palay, 1991; German et al., 1992).

In summary, the present results suggest that $\mathrm{CRH}$ and the locus coeruleus may function as an integral part of a regulatory system that is capable of modulating immunologic responses. Increases in activity within this neural substrate may contribute to the modulatory effects of stressors or CNS CRH systems on cellular immune responses. Further research is necessary to characterize how alterations in brain function during immunologic challenges effect the dynamic equilibrating interactions of the central nervous, endocrine, sympathetic nervous, and immune systems.

\section{References}

Abercrombie ED, Jacobs BL (1987) Single unit response of noradrenergic neurons in locus coeruleus of freely moving cats. I. Acutely presented stressful and nonstressful stimuli. J Neurosci 7:2837-2843.
Aston-Jones G, Shipley MT, Chouvet G, Ennis M, Van Bockstaele EJ, Pieribone V, Shiekhattar R, Akaoka H, Drolet G, Astier B, Charlety P, Valentino R, Williams JT (1991) Afferent regulation of locus coeruleus neurons: anatomy, physiology and pharmacology. Prog Brain Res 85:47-75.

Britton DR, Koob GF, Rivier J, Vale W (1982) Intraventricular corticotropin-releasing factor enhances behavioral effects of novelty. Life Sci 31:363-367.

Brown MR, Fisher LA, Spiess J, Rivier C, Vale W (1982) Corticotropin-releasing factor (CRF): actions on the sympathetic nervous system and metabolism. Endocrinology 111:928-931.

Butler PD, Weis JM, Stout JC, Nemeroff CB (1990) Corticotropinreleasing factor produces fear-enhancing and behavioral activating effects following infusion into the locus coeruleus. J Neurosci 10:176183.

Carlson DE, Gann DS (1991) Response of plasma adrenocorticotropin to injections of L-glutamate or norepinephrine in the dorsal rostral pons of cats. Endocrinology 128:3012-3031.

Chan-Palay V (1991) Alterations in the locus coeruleus in dementias of Alzheimer's and Parkinson's disease. Prog Brain Res 88:625-630.

Chappell P, Smith M, Kilts C, Bissette G, Ritchie J, Anderson C, Nemeroff CB (1986) Alterations in corticotropin-releasing factor-like immunoreactivity in discrete rat brain regions after acute and chronic stress. J Neurosci 6:2908-2914.

Cummings S, Elde R, Ells J, Lindall A (1983) Corticotropin-releasing factor immunoreactivity is widely distributed within the central nervous system of the rat: immunohistochemical study. J Neurosci 3:13551368.

Cunnick JE, Lysle DT, Kucinski BJ, Rabin BS (1990) Evidence that shock-induced immune suppression is mediated by adrenal hormones and peripheral $\beta$-adrenergic receptors. Pharmacol Biochem Behav 36: 645-651.

Curtis AL, Drolet G, Valentino RJ (1993) Hemodynamic stress activates locus coeruleus neurons of unanesthetized rats. Brain Res Bull 31:737-744.

Danzer R, Kelly KK (1989) Stress and immunity: an integrated view of relationships between the brain and the immune system. Life Sci 44:1995-2008.

De Sarro GB, Fratta W, Giglio A, Nistico G (1992) Electrocortical power spectrum changes induced by microinfusion of corticotropinreleasing factor into the locus coeruleus in rats. Funct Neurol 7:407412.

De Souza EB (1987) Corticotropin-releasing factor receptors in the rat central nervous system: characterization and regional distribution. J Neurosci 7:88-100.

Dunn AJ, Berridge CW (1990) Physiological and behavioral responses to corticotropin-releasing factor administration: is CRF a mediator of anxiety or stress responses? Brain Res Rev 15:71-100.

Eaves M, Thatcher-Britton K, Rivier J, Vale W, Koob GF (1985) Effects of corticotropin-releasing factor on locomotor activity in hypophysectomized rats. Peptides 6:923-926.

Ehlers CL, Henriksen SJ, Wang M, Rivier J, Vale W, Bloom FE (1983) Corticotropin releasing factor produces increases in brain excitability and convulsive seizures in rats. Brain Res 278:322-336.

Fisher LA (1989) Corticotropin-releasing factor: endocrine and autonomic integration of responses to stress. Trends Pharmacol Sci 10: 189-193.

Foote SL, Aston-Jones G, Bloom FE (1980) Impulse activity of locus coeruleus neurons in awake rats and monkeys is a function of sensory stimulation and arousal. Proc Natl Acad Sci USA 77:3033-3037.

Foote SL, Bloom FE, Aston-Jones G (1983) Nucleus locus coeruleus: new evidence of anatomical and physiological specificity. Physiol Rev 63:844-914.

German DW, Manaye KB, White CL, Woodward DJ, McIntire DD, Smith WK, Kalaria RN, Mann DA (1992) Disease-specific patterns of locus coeruleus cell loss. Ann Neurol 32:667-676.

Gold PW, Loriaux DL, Roy A, Kling MA, Calabrese JR, Kellner CH, Nieman LK, Post RM, Pickar D, Gallucci W, Averginos P, Paul S, Oldfield EH, Cutler GB Jr, Chrousos PG (1986) Response to corticotropin-releasing hormone in the hypercortisolism of depression and Cushing's disease. N Engl J Med 314:1329-1342.

Holsboer F, von Bardeleben U, Gerken A, Stalla GK, Muller OA (1984) Blunted corticotropin and normal cortisol response to human corticotropin-releasing factor in depression. N Engl J Med 31 1:1127-1133. Irwin M (1993) Brain corticotropin-releasing hormone and interleu- 
kin-induced suppression of specific antibody production. Endocrinology 133:1352-1360.

Irwin M, Vale W, Britton KT (1987) Central corticotropin-releasing factor suppresses natural killer cytotoxicity. Brain Behav Immunol $1: 81-87$.

Irwin M, Hauger R, Brown M (1992) Central corticotropin-releasing hormone activates the sympathetic nervous system and reduces immune function: increased responsitivity of the aged rat. Endocrinology 131:1047-1053.

Jain R, Zxickler D, Hollander CS, Brand H, Saperstein A, Hutchinson B, Brown C, Audhya T (1991) Corticotropin-releasing factor modulates the immune response to stress in the rat. Endocrinology 128: $1329-1336$.

Judd AM, Spangelo BL, MacLeod RM (1990) Rat zona glomerulosa cells produce interleukin 6 . Prog Neuroendocrimmunol 3:282-292.

Keller SE, Weiss JM, Schleiffer SJ, Miller NE, Stein M (1983) Stressinduced suppression of immunity in adrenalectomized rats. Science 221:1301-1304.

Keller SE, Schleifer SD, Demetrikopoulous MK (1991) Stress-induced changes in immune function in animals: hypothalamo-pituitary-adrenal influences. In: Psychoneuroimmunology (Ader R, Felten DL, Cohen N, eds), pp 771-788. New York: Academic.

Komori T, Nakano T, Ohsugi Y (1987) Alleviation of depressed immunity caused by restraint-stress, by the immunomodulator, lobenzarit disodium (disodium 4-chloro-2,2'-iminodibenzoate). Int J Immunopharmacol 9:433-441.

Koob GF, Bloom FE (1985) Corticotropin-releasing factor and behavior. Fed Proc 44:259-263.

Korf J, Aghajanian GK, Roth RH (1973) Increased turnover of norepinephrine in the rat cerebral cortex during stress: role of the locus coeruleus. Neuropharmacology 12:933-938.

Lacheur J, Gailler S, Barbagli B, Buda M, Tappaz M (1991) Differential early time course activation of the brainstem catecholaminergic groups in response to various stresses. Neuroendocrinology 53:589-596.

Lysle DT, Cunnick JE, Fowler H, Rabin BS (1988) Pavlovian conditioning of shock-induced suppression of lymphocyte reactivity: acquisition, extinction, and preexposure effects. Life Sci 42:2185-2194.

Lysle DT, Cunnick JE, Rabin BS (1990a) Stressor-induced alteration of lymphocyte proliferation in mice: evidence for enhancement of mitogenic responsiveness. Brain Behav Immunol 4:269-277.

Lysle DT, Cunnick JE, Kucinski BJ, Fowler. H, Rabin BS (1990b) Characterization of immune alterations induced by a conditioned aversive stimulus. Psychobiology 18:220-226.

Maier SF, Laudenslager ML (1988) Inescapable shock, shock controllability, and mitogen stimulated lymphocyte proliferation. Brain Behav Immunol 2:87-91.

Melia KR, Duman RS (1991) Involvement of corticotropin-releasing factor in chronic stress regulation of the brain noradrenergic system. Proc Natl Acad Sci USA 88:8382-8386.

Melia KR, Rasmussen K, Terwilliger RZ, Haycock JW, Nestler FJ, Duman RS (1992) Coordinate regulation of cyclic AMP system with firing rate and expression of tyrosine hydroxylase in the rat locus coeruleus: effects of chronic stress and drug trcatments. J Neurochem 58:494-502.

Merchenthaler I, Vigh S, Petrusz P, Schally AV (1982) Immunocytochemical localization of corticotropin-releasing factor (CRF) in rat brain. Am J Anat 165:385-396.

Mezey E, Palkovits M (1991) CRH-containing neurons in the hypothalamic paraventricular nucleus: regulation, especially by catecholamines. Front Neuroendocrinol 12:23-27.

Miyawaki T, Kawamura H, Komatsu K, Yasugi T (1991) Chemical stimulation of the locus coeruleus: inhibitory effects on hemodynamics and renal sympathetic nerve activity. Brain Res 568:101-108.

Moore RY, Card JP (1984) Noradrenaline-containing neuron systems. In: Handbook of chemical neuroanatomy, Vol 2, Classical transmitters in the CNS, Pt I (Bjorklund A, Hokfelt T, eds), pp 123-156. Amsterdam: Elsevier.

Nemeroff CB, Widerlov E, Bissette G, Walleus H, Karlsson K, Kilts CD, Loosen PT, Vale W (1984) Elevated concentrations of CSF corticotropin-releasing factor-like immunoreactivity in depressed patients. Science 226:1342-1344.

Paxinos G, Watson C (1986) The rat brain in stereotaxic coordinates. San Diego: Academic.

Pezzone MA, Rush KA, Kusnecov A, Wood PG, Rabin BS (1992)
Corticosterone-independent alteration of lymphocyte mitogenic function by amphetamine. Brain Behav Immunol 6:293-299.

Pezzone MA, Lee WS, Hoffman GE, Pezzone KM, Rabin BS (1993) Activation of brainstem catecholaminergic neurons by conditioned and unconditioned aversive stimuli as revealed by c-Fos immunoreactivity. Brain Res 608:310-318.

Philippu A, Denmeler R, Roensberg G (1974) Reduced blood pressure response to locus coeruleus stimulation. Naunyn Schmiedebergs Arch Pharmacol 282:389-400.

Plotsky PM, Cunningham ET, Widmaier EP (1989) Catecholaminergic modulation of corticotropin-releasing factor and adrenocorticotropin secretion. Endocr Rev 10:437-458.

Rabin BS, Cohen S, Ganguli R, Lysle DT, Cunnick J (1989) Bidirectional interaction between the central nervous system and the immune system. Crit Rev Immunol 9:279-312.

Richard F, Faucon Biquet N, Labatut R, Rollet D, Mallet J, Buda M (1988) Modulation of tyrosine hydroxylase gene expression in rat brain and adrenal by exposurc to cold. J Neurosci Res 20:32-37.

Roszman TL, Brooks WH (1985) Neural modulation of immune function. J Neuroimmunol 10:59-69.

Sakanaka M, Shibasaki, Lederis K (1987) Corticotropin-releasing factor-like immunoreactivity in the rat brain as revealed by modified cobalt-glucose oxidase-diaminobenzidine method. J Comp Neurol 260:256-298

Singh VK, Fudenberg HH, Brown FR III (1987) Immunologic dysfunction: simultaneous study of Alzheimer's and older Down's patients. Mech Ageing Dev 37:257-265.

Solomon GF (1987) Psychoneuroimmunology: interactions between the central nervous system and immune system. J Neurosci Res 18: $1-9$.

Straubaugh H, Irwin M (1992) Central corticotropin-releasing hormone reduces cellular immunity. Brain Behav Immunol 6:11-17.

Sutton R, Koob G, Le Moal M, Rivier J, Vale W (1982) Corticotropin releasing factor (CRF) produces hehavioral activation in rats. Nature 299:331-333.

Sved AF, Felsten G (1987) Stimulation of the locus coeruleus decrease artcrial pressurc. Brain Res 414:119-132.

Swanson LW, Sawchenko PE, Rivier J, Vale W (1983) The organization of ovine corticotropin releasing factor (CRF)-immunoreactive cells and fibers in the rat brain: an immunohistochemical study. Neuroendocrinology 36:165-186.

Swiergiel AH, Takahashi LK, Rubin WW, Kalin NH (1992) Antagonism of corticotropin-releasing factor receptors in the locus coeruleus attenuates shock-induced freezing in rats. Brain Res 587:263-238.

Tavalato B, Argentiero V (1980) Immunological indices in presenile Alzheimer's disease. J Neurol Sci 46:326-331.

Thrivikraman KV, Plotsky PM, Gann DS (1993) Alterations of locus coeruleus noradrenergic activity in relation to pituitary secretion after hemorrhage in cats. Neurosci Lett 161:85-88.

Valentino RJ, Foote SL (1987) Corticotropin-releasing factor disrupts sensory responses of brain noradrenergic neurons. Neuroendocrinology 45:28-36.

Valentino RJ, Foote SL (1988) Corticotropin-releasing hormone increases tonic but not sensory evoked activity of noradrenergic locus coeruleus neurons in unanesthetized rats. J Neurosci 8:1016-1025.

Valentino KJ, Wehby RG (1988) Corticotropin-releasing factor: evidence for a neurotransmitter role in the locus coeruleus during hemodynamic stress. Neuroendocrinology 48:674-677.

Valentino RJ, Foote SL, Aston-Jones G (1983) Corticotropin-releasing factor activates noradrenergic neurons of the locus coeruleus. Brain Res 270:363-367.

Valentino RJ, Page ME, Curtis AL (1991) Activation of noradrenergic locus coeruleus neurons by hemodynamic stress is due to local release of corticotropin-releasing factor. Brain Res 555:25-34.

Valentino RJ, Page M, Van Bockstaele E, Aston-Jones G (1992) Corticotropin-releasing factor innervation of the locus coeruleus: distribution of fibers and sources of input. Neuroscience 48:689-705.

Wan W, Vriend CY, Wetmore, L, Gartner JG, Greenberg AH, Nance DM (1993) The effects of stress on splenic immune function are mediated by the splenic nerve. Brain Res Bull 30:101-105.

Ward DG, Gun CG (1976) Locus coeruleus complex: elicitation of a pressor response and brain stem region necessary for its occurrence. Brain Res 107:401-406.

Weiner N, Hossain MA, Masserano JM (1991) The cffects of clectro- 
convulsive shock on catecholamine function in the locus coeruleus and hippocampus. J Neural Transm [Suppl] 34:3-9.

Zhou D, Kusnecov AW, Shurin MR, DePaoli M, Rabin BS (1993) Exposure to physical and psychological stressors elevates plasma interleukin 6: relationship to the activalion of hypothalamic-pituitaryadrenal axis. Endocrinology 133:2523-2530.
Zigmond RE, Schon F, Iversen LL (1974) Increased tyrosine hydroxylase activity in the locus coeruleus of rat brain after reserpine treatment and cold stress. Brain Res 70:547-552. 